\title{
THE MEAN DISTANCE TO THE MOON AS DETERMINED BY RADAR
}

\author{
By B. S. YAPLEE, S. H. KNOWLES, \\ A. SHAPIRO, K. J. GRAIG, \\ U.S. Naval Research Laboratory Radio Astronomy Branch, \\ Washington, D. C. \\ and D. BROUWER, \\ Yale University Observatory, \\ New Haven, Connecticut.
}

RÉsumé. - Les auteurs donnent les résultats des mesures de la distance de la Lune à l'aide d'échos-radar effectuées en 1959-1960. Ils décrivent les méthodes de réduction et discutent les erreurs d'origines différentes, en particulier celles dues à la topographie de la Lune. Ils discutent également les effets des autres constantes comme les rayons de la Terre et de la Lune.

Abstract. - The results of i 959 - I 960 radar measurements of the distance of the Moon are given. The method of reduction of the data is described The possible effects of lunar topography and errors of other origins are discussed, as well as the effects of different constants such as the radii of the Earth and of the Moon.

Zusammenfassung. - Die Ergebnisse der i959-1960 durchgeführten Radar-Messungen der Entfernung des Mondes werden angegeben und die Reduktionsmethoden beschrieben. Die möglichen Einflüsse der Mondtopographie und von Fehlern anderer Ursache werden diskutiert, ebenso die Effekte verschiedener Konstanten wie der Radien von Erde und Mond.

Резюме. - Авторы дают результаты измерений расстояния до Луны радаром в 1959-1960 г. Они описывают методы редукции, обсуждают влияние разных ошибок, в частности тех, которые вызванны топографией Луны. Они также обсуждают влияние других постоянных, как например радиусов Земли и Луны.

Symposium C. A. I., $n^{\circ} 21$. 
82 B. S. YAPLEE, S. H. KNOWLES, A. SHAPIRO, K. J. CRAIG, D. BROUIVER.

Introduction. - The first systematic radar measurements of the distance to the Moon were made at the U. S. Naval Research Laboratory in 1957 [1]. Residuals (radar distance minus calculated distance) were derived from data taken over a one-month period. These residuals suggested a periodic pattern and a peak-to-peak amplitude variation of about $3 \mathrm{~km}$. Ignoring this variation, which was believed to be caused primarily by the topographic features of the Moon, the mean lunar distance was derived and reported as $384402\left({ }^{1}\right) \pm \mathrm{I.2} \mathrm{km}$ using a lunar radius of $1740 \pm 1.2 \mathrm{~km} \mathrm{[2].} \mathrm{To} \mathrm{investigate} \mathrm{the} \mathrm{possibility} \mathrm{that}$ the variation of the 1957 residuals was due mainly to the lunar topography, an extended observation program was initiated in late 1959 and continued through the middle of 1960 (about eight-lunations). During this period the nearest point of the Moon as seen. from the observing site traces roughly the same ellipse on the lunar surface during each lunation (fig. I). Therefore, by relating the range measurements from several months to the same general areas on the Moon's surface, it was possible to remove the topography from the distance measurements and compute a mean distance referred uniquely to a mean radar surface of the Moon.

The accuracy of the $1959-1960$ radar measurements was increased by enhancing the sensitivity of the radar system, and improving the data reduction technique. However, as radar measures time and not distance, the derived distance is affected by any uncertainty in the velocity of propagation. Furthermore the derived center-to-center Earth-Moon distance depends on the uncertainties of the assumed values of the Moon's radius as referred to the mean radar surface, and the Earth's radius at the observing site.

Radar observations. - The experiment was carried out with essentially the same equipment (a modified APS-20 E radar system and the 5o-ft. antenna) as previously reported by Yaplee et al. [1]. Mounting the receiver and duplexer at the focus of the antenna reduced the receiver insertion loss, and suspending the transmitter in a pendulum-like cradle permitted full sky coverage. A parametric amplifier replaced the traveling wave tube as the $\mathrm{R}$. $\mathrm{F}$. amplifier. This reduced the noise factor to about $3 \mathrm{db}$ as reported by Wrigley et al. [3].

The time measurements of the radar echoes were taken relative to a reference pulse. Figure $2 a$ shows the time sequence of the radar pulses. The radar transmits a series of $2 \mu$ s pulses at a repetition rate of approximately 300 pulses/s. The round trip time of the radar pulse

(1) This result is reduced to $384400 \pm 1.2 \mathrm{~km}$ by using $1738 \pm \mathrm{I} \mathrm{km}$ for the lunar radius. 


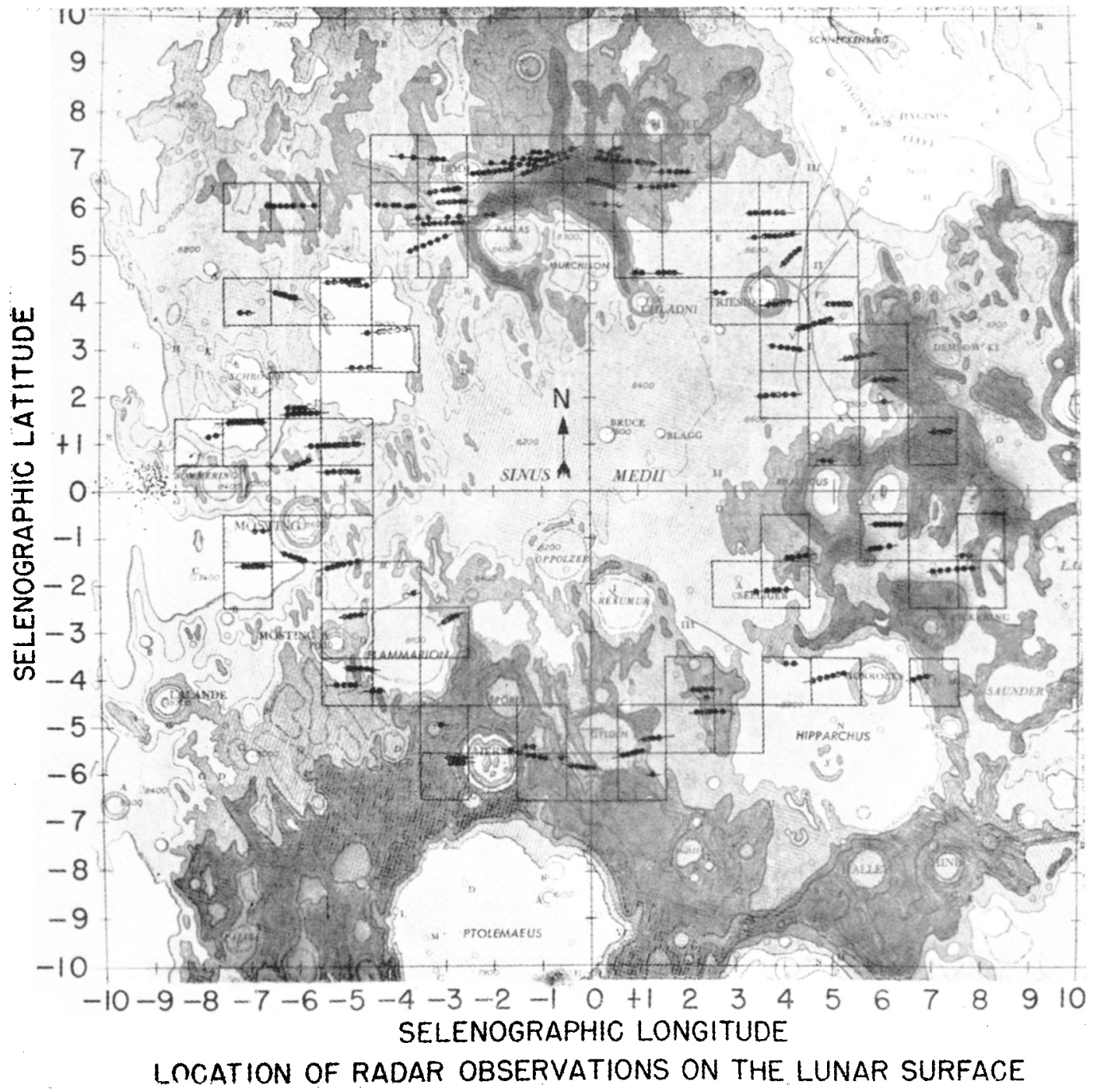

Fig. I. - Iocation of radar observations on the lunar surface. 
is equal to an integral number of repetition periods plus a fraction of a period. It is sufficient to measure accurately the time of the leading edge of the echo with respect to the last transmitted pulse to obtain the radar distance, since the lunar distance is known well within one pulse repetition period.

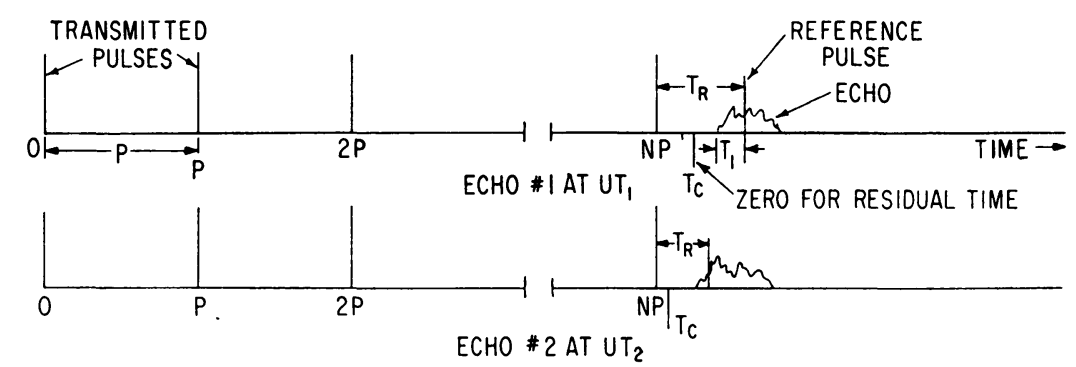

(a) TIME SEQUENCE OF RADAR PULSES
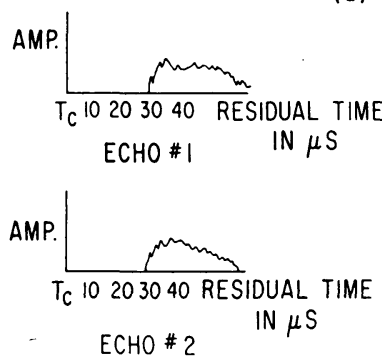

$$
\begin{aligned}
& P \text { - REPETITION PERIOD } \\
& T_{C} \text { - CALCULATED ROUND TRIP TIME } \\
& T_{R} \text {-DELAY OF REFERENCE PULSE } \\
& \text { UT - UNIVERSAL TIME } \\
& N \text { - NO. OF PERIODS BEFORE ECHO } \\
& T_{1} \text { - TIME OF LEADING EDGE OF ECHO WITH } \\
& \text { RESPECT TO THE REFERENCE PULSE }
\end{aligned}
$$

(b) CONVERSION TO RESIDUAL TIME

Fig. 2. - Time sequences of radar pulses and conversion to residual time.

Data reduction. - The output data were recorded on $35 \mathrm{~mm}$ film with about 450 radar echoes photographically superimposed on each frame. An example of a film frame is shown in figure 3. Photographic integration reduces the effect of signal fluctuations on the recorded radar return. Also shown in figure 3 is a series of $10 \mu$ s ( $1500 \mathrm{~m}$ ) range marks. The time position of the echo is measured with respect to the reference pulse, which in general is located near the start of the echo. The delay of the reference pulse is measured with high accuracy with respect to the preceding transmitted pulse, and recorded separately.

The echoes were photographed at frequent intervals for several hours during each day of observations. Figure I shows the approximate area on the Moon's disk for each observation. Each photographed echo was digitized and punched on I. B. M. cards for convenient data reduction. 
84 B. S. YAPLEE, S. H. KNOWLES, A. SHAPIRO, K. J. CRAIG, D. BROUWER.

To compute corrections to the lunar distance, the theoretically calculated round trip time of each echo was subtracted from the measured round trip time, effectively shifting the time origin to a residual origin. The theoretically calculated distance is derived from the geometry of

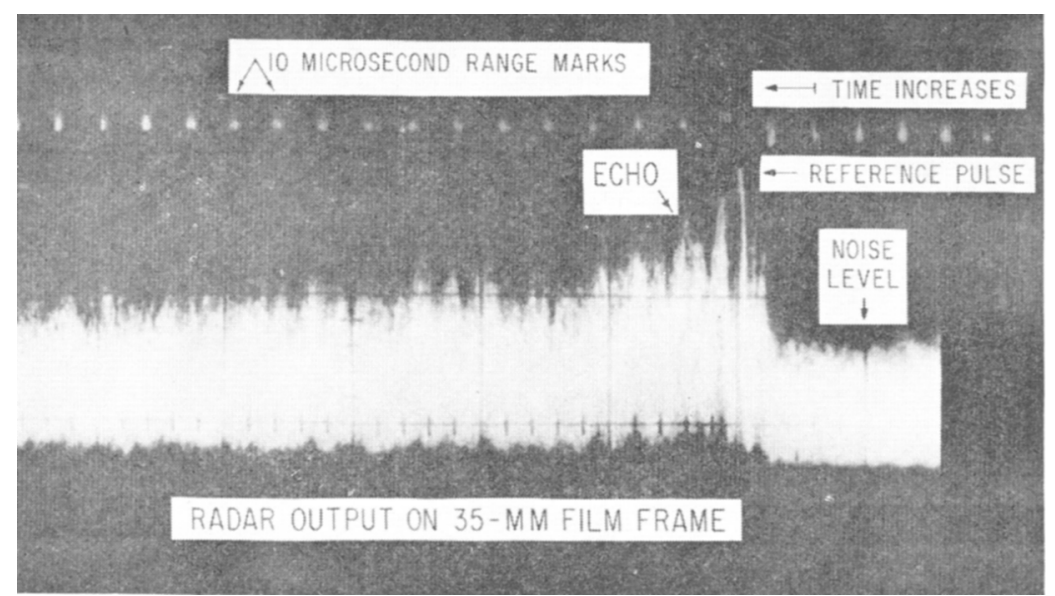

Fig. 3. - Example of a film frame recording of the radar echoes.

the Earth-Moon system as shown in figure 4 and converted to time by

$$
\mathbf{T}_{c}=\frac{2}{c} p
$$

where

$$
p=-b+\left(r^{2}+s^{2}-2 r s \cos \beta\right)^{\frac{1}{2}}
$$

and

$$
\cos \beta=\sin \varphi^{\prime} \sin \hat{o}+\cos \varphi^{\prime} \cos \hat{o} \cos \gamma
$$

$b$, lunar radius to apparent disk center;

$r$, observer's radius vector;

$s$, predicted center-to-center distance $=\frac{a}{\sin \pi \mathbb{C}} ;$

$a$, Earth's equatorial radius;

$\pi_{0}$, Moon's equatorial horizontal parallax;

$\varphi^{\prime}$, geocentric latitude of NRL;

$\delta$, declination of the Moon;

$\because$, Moon's local hour angle. 
Table I gives the numerical values used for the various constants in equation ( $\mathrm{r}$ ). Also listed is $\Delta \mathrm{T}$, the correction from $U$.T. to ephemeris time used in the calculations. The center-to-center distances were computed using interpolated values from the Improved Lunar Ephemeris for the Moon's parallax, with an Earth's equatorial radius of $6378270 \mathrm{~m}$. Consequently, the theoretically calculated distance

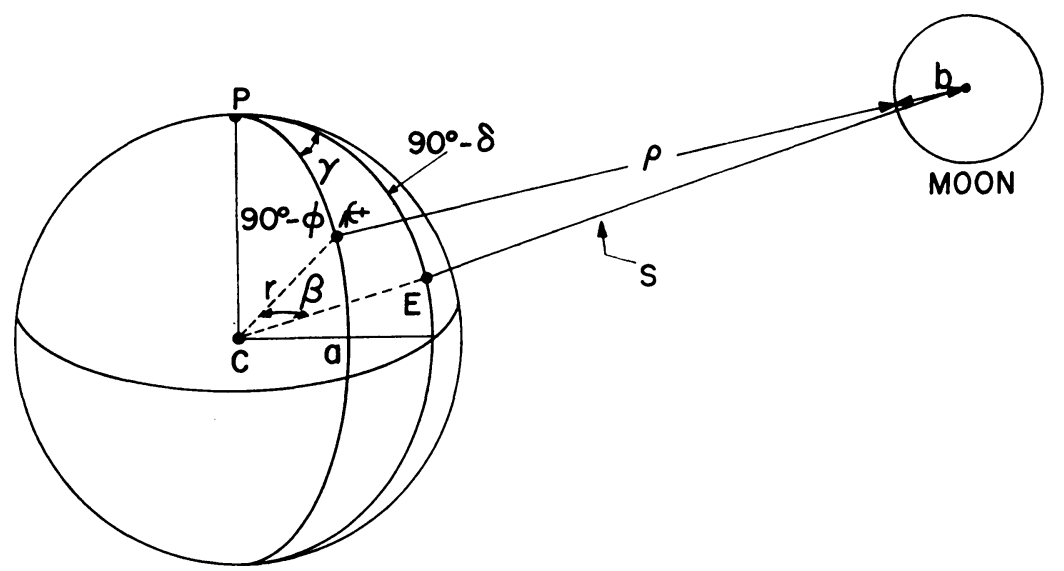

EARTH

Fig. 4. - Diagram of the Earth-Moon distance problem.

is referred to a reference mean distance $s_{1}$ as given in table I where the choice of $s_{0}$ was a matter of convenience, since it was to be corrected by the radar measurements.

TABLE I.

Constants used in the computation of radar distance to the Moon.

$$
\begin{aligned}
c & =2.997928 \times 10^{8} \mathrm{~m} / \mathrm{s} \pm 300 \mathrm{~m} / \mathrm{s} \\
b & =1738 \mathrm{~km} \pm \mathrm{I} \mathrm{km} \\
r & =63699^{36 \mathrm{~m}} \\
\mathrm{P}^{\prime}= & 38037^{\prime} 59.8^{\prime \prime} \mathrm{N} \\
\Delta \mathrm{T}= & +33.0 \mathrm{~s}(1959) \\
& +34.0 \mathrm{~s}(1960) \\
s_{0}= & \frac{a}{\sin \bar{\pi}_{\mathbb{C}}}=384396.600 \mathrm{~km} \\
a= & 6378270 \mathrm{~m} \\
\left(\sin \bar{\pi}_{\mathbb{C}}\right)^{\prime \prime}= & 3422^{\prime \prime} .5400 \\
\sin \bar{\pi}_{\mathbb{C}} & =0.016592942
\end{aligned}
$$


The value of $r$ given in table I is the distance of the NRL radar installation from the center of the Earth, computed with the elliptic formula

$$
r=\frac{a(\mathrm{I}-f)}{\sqrt{\mathrm{I}-\left(2 f-f^{2}\right) \cos ^{2} \varphi^{\prime}}}+h,
$$

in which for the oblateness $f=\frac{I}{298.3}$ and for the elevation above sea level $h=26 \mathrm{~m}$ were used.

The measured round trip time is derived from the time position of the echoes relative to the reference pulse as

$$
\mathrm{T}_{\mathrm{A}}=\mathrm{NP}+\mathrm{T}_{\mathrm{R}} \pm \mathrm{T}_{1}
$$

where the symbols are defined in figure 2.

Due to the relative motion of the observer and the Moon, the recorded echo is continually moving in range. However the residual echo remains stationary for longer periods. Figure 2 illustrates this with two echoes whose time of arrival are different. When the theoretically calculated round trip time is subtracted from the measured round trip time, the two echoes coincide (fig. $2 b$ ).

Since the gross effects of the Moons's relative motion are now removed, echoes can be averaged over longer intervals to increase the accuracy of the measurements. Echoes were usually averaged over 3o minutes intervals (about 35 frames). This interval is short enough, so that the time varying effects on the resultant average echo caused by uncertainties of the constants and any change of topography are negligible. Figure 5 illustrates a resultant average echo.

The reading of the residual time of the leading edge of the averaged echo is to some extent arbitrary, since the echo, even after the averaging process is of a complex nature, which varies with different areas on the Moon. Some compromise had to be made to obtain residuals, which would be both consistent over many readings and correspond to the initial return of the radar pulse. Three methods were tried.

In the first method (initial time) the residual time was read at the point, where the echo emerged from the noise. As some echoes were close to the noise level for several microseconds, it was difficult to obtain consistent readings.

In the second method (slope) the residual time was read at the intersection of the line drawn tangent to the point of maximum initial slope of the echo and the mean noise level.

In the third method (one-half amplitude) the residual time was read at the point on the residual time axis which corresponds to one-half the first maximum amplitude of the echo.

The slope method shown in figure 5 was finally adopted for computation because it was as consistent as the one-half amplitude method, but corresponded more nearly to the residual time of the leading edge. 
The observation equation obtained from equation ( $\mathrm{I}$ ) is

$$
k_{2} x=\Delta_{p}-k_{1} \Delta r+\Delta b+\frac{\tilde{q}}{c} \Delta c,
$$

where $J r$ is the correction to the Earth's radius at the observing site, and $x$ the correction to the mean distance $s_{0}$ defined by

$$
x=\frac{\Delta s}{s} s_{0} .
$$

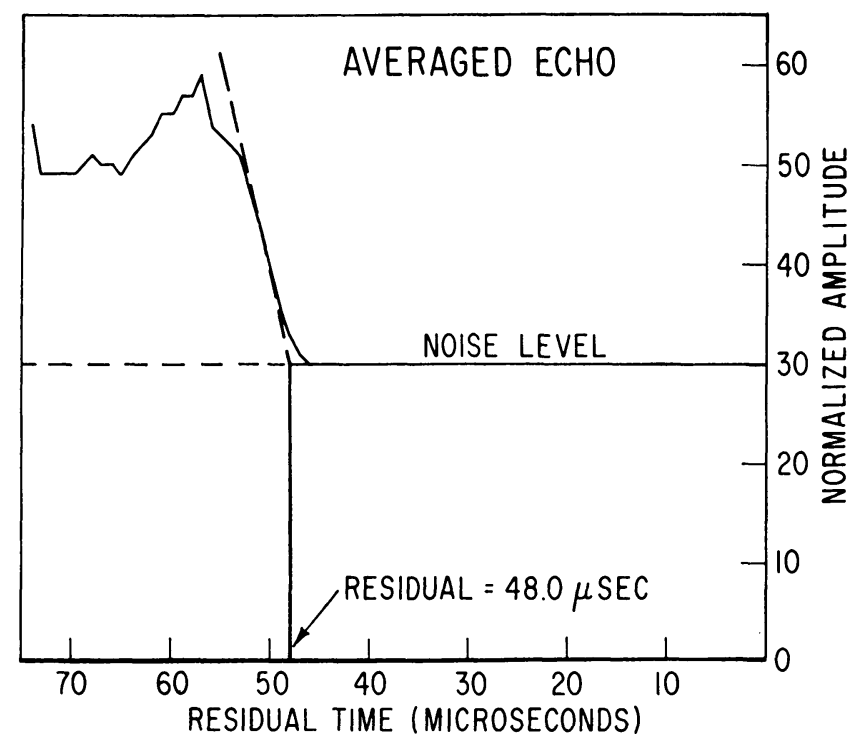

Fig. 5. - Diagram of an average resultant echo.

The coefficients are

$$
\begin{gathered}
k_{1}=\frac{r-s \cos \beta}{\rho+b}, \\
k_{2}=\frac{s-r \cos \beta}{\rho+b} \frac{s}{s_{0}} .
\end{gathered}
$$

Since $x, \Delta r, \Delta b$, and $\Delta c$ cannot be adequately separated in a solution by least squares, $\Delta r, \Delta b$ and $\Delta c$ were kept in the right-hand member of the observation equation and the normal equation.

Further discussion of the data reduction is given in the next section.

Discussion and results. - The distance obtained from the radar measurements is the distance from the observing site to the nearest reflecting region on the Moon's surface. The accuracy of the distance measurements depends primarily on the accuracy of the value of the 


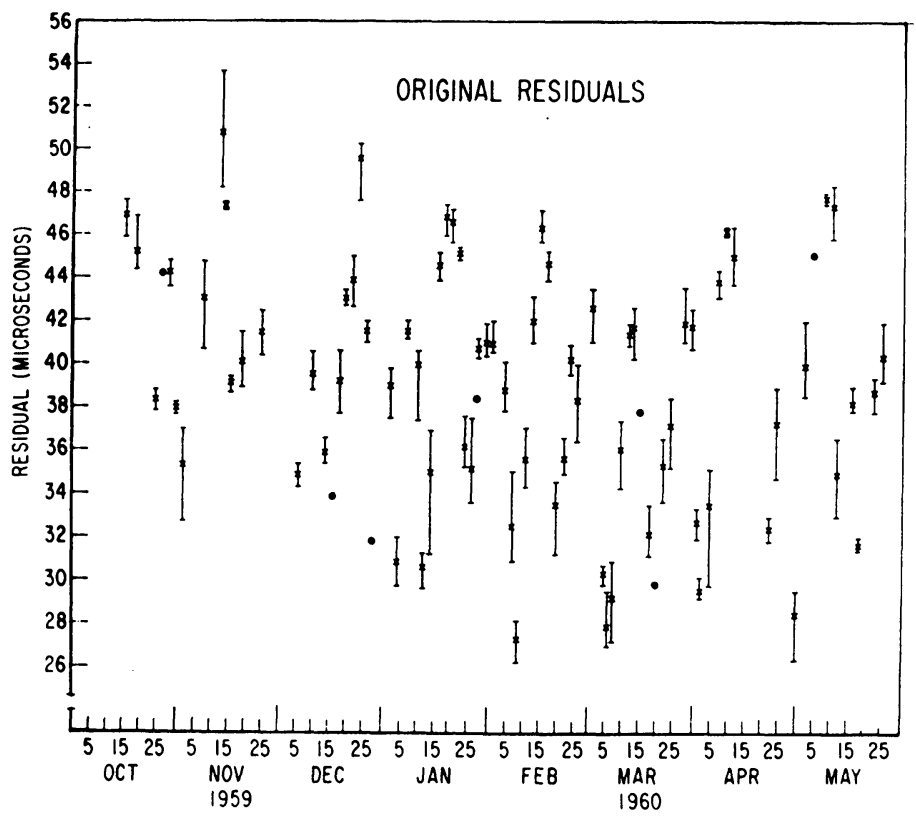

Fig. $6 a$. - Residuals of $1959-1960$ observation.

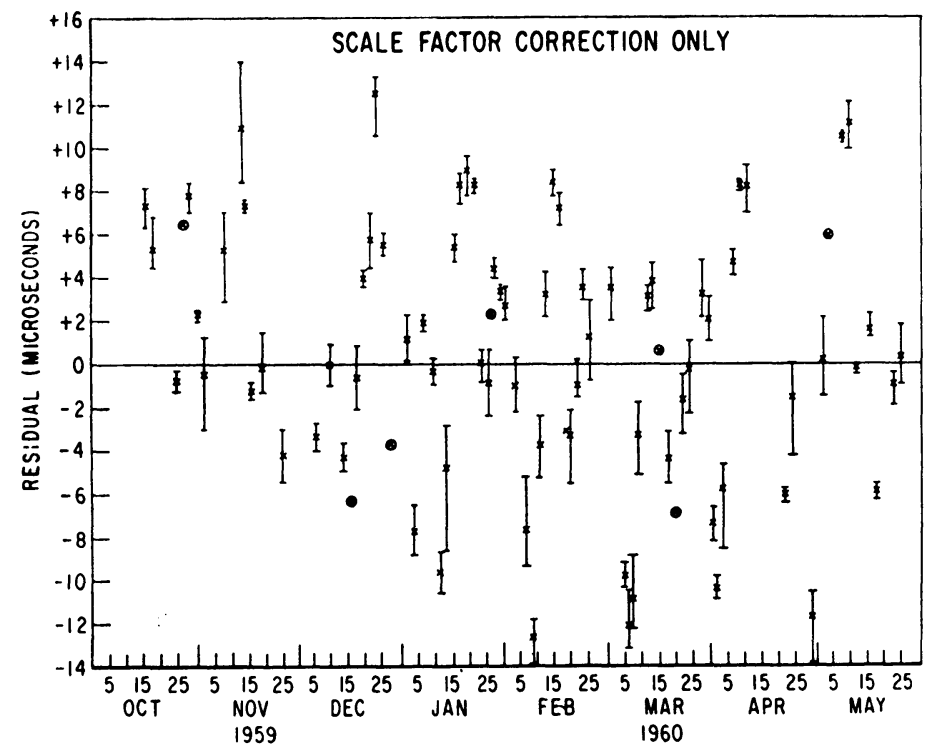

Fig. $6 b$. - Residuals of $1959-1960$ observation. 
THE MEAN DISTANCE TO THE MOON.

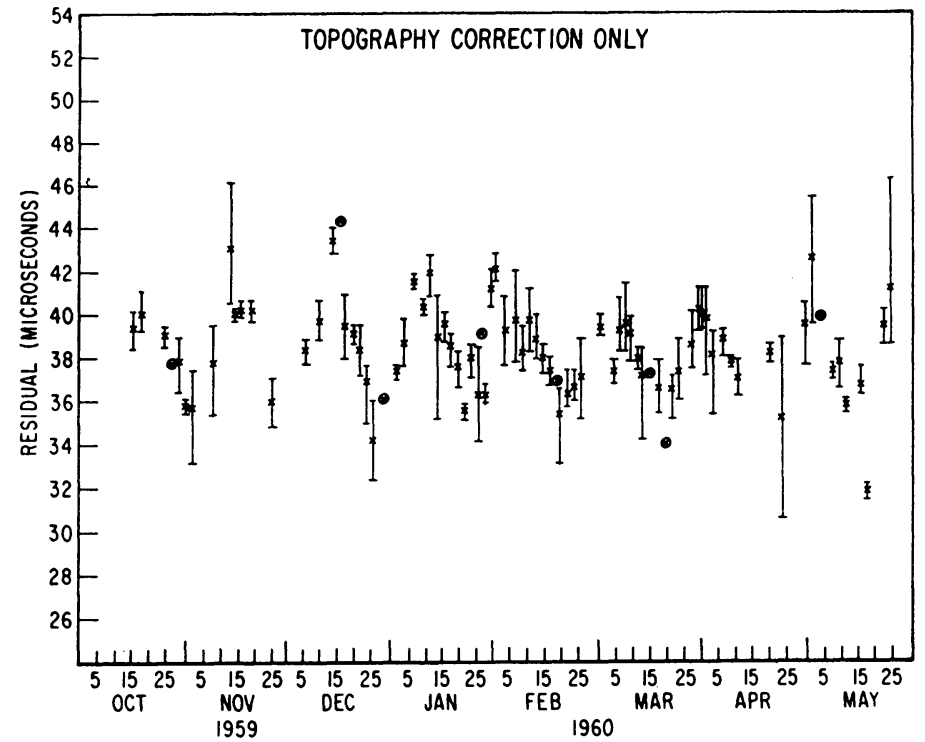

Fig. $6 c$. - Residuals of 1959 - 1960 observation.

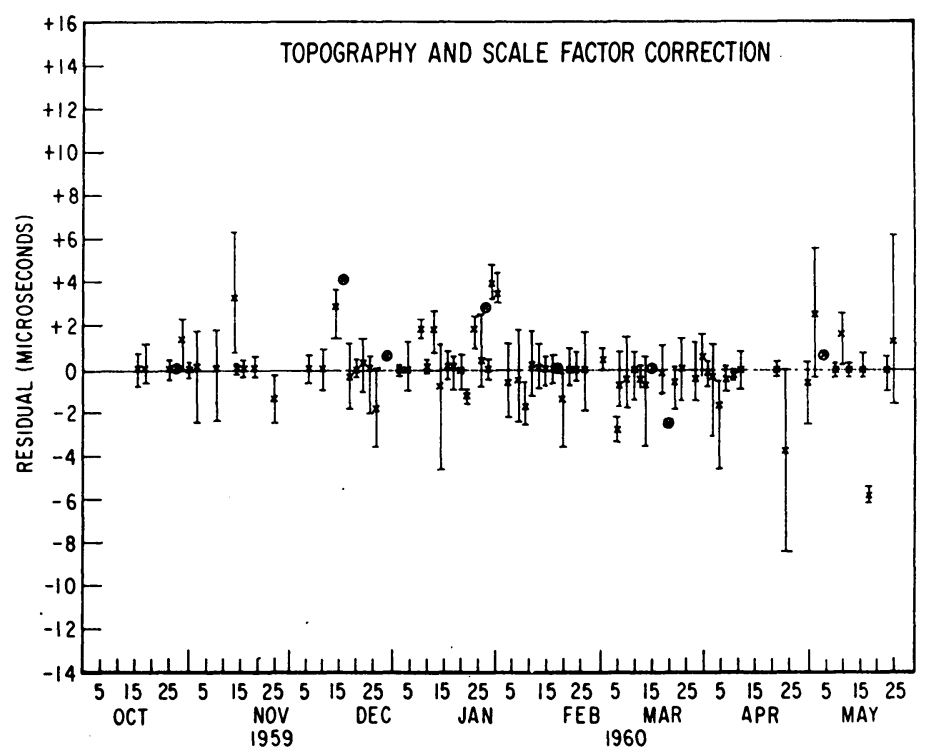

Fig. $6 d$. - Residuals of $19^{59-1960}$ observation. 
go B. S. YAPLEE, S. II. KNOWLES, A. SHAPIRO, K. J. CRAIG, D. BROUWER.

velocity of radio wave propagation that is used to convert from time to distance. Other errors are introduced by :

1. the jitter of the synchronizing pulses;

2. the uncertainty of the exact location of the area of reflection;

3. the uncertainty of the time position of the leading edge of the echo in the noise.

At a wavelength of $10 \mathrm{~cm}$, which is used as the carrier frequency of the radar, the effect of the cis-lunar medium on the velocity of propagation is probably insignificant. Therefore, the velocity of propagation can be set equal to the free space value whose uncertainty may contribute an error of $\pm 400 \mathrm{~m}$ to the radar distance.

The synchronizing system of the radar is controlled by a highly stable frequency source, and great care was taken to minimize pulse to pulse jitter. The resultant jitter was less than one part in $10^{8}( \pm 5 \mathrm{~m})$.

The NRL radar was capable of distinguishing changes in distance of less than $300 \mathrm{~m}$. In the central region of the Moon's visible disk, from which the radar pulses were reflected, there are local changes in surface heights of the order of $4000 \mathrm{~m}$. Although the radar method used had poor angular resolution, one may infer from the steepness of the averaged echo that the leading edge of the echo must have returned from an area of not greater than $3^{\circ}$ of lunar angle (or $90 \mathrm{~km}$ ) from the sub-Earth point. Since the total libration amounts to about \pm 8 lunar degrees in latitude and longitude, one may expect range variations due to the topography of the different reflecting areas.

A plot of the residuals for the $1959-1960$ observations shows periodic changes in range which the discussion of the data shows to be related to topographic variations (see fig. 6a). As discussed previously, the variations of the residuals were analyzed by a least square solution to see whether after removing the distance correction, the corrected residuals could be related to the topography of the lunar surface. In figure $6 b$ the least square residuals exhibit variations of $\pm 2 \mathrm{~km}$. When the least square residuals for the same regions of the lunar surface but separated in time by several months, were averaged in $\mathrm{I}^{0}$ squares, (producing an equivalent radar map) it was noted that over $90 \%$ of the areas (about 70 regions) had an r. m. s. scatter less than $300 \mathrm{~m}$, while the radar heights between different regions varied by $3600 \mathrm{~m}$ ( fig. 7). This consistency of the radar measurements confirmed the expectation that the variations of the residuals are related to specific areas on the Moon. The derived radar map was also compared with an equivalent optical map obtained from the Army Map Service (fig. 7) and, as can be seen, fair agreement has been obtained for most areas. The reason for the few discrepancies is being investigated. A computation neglecting 


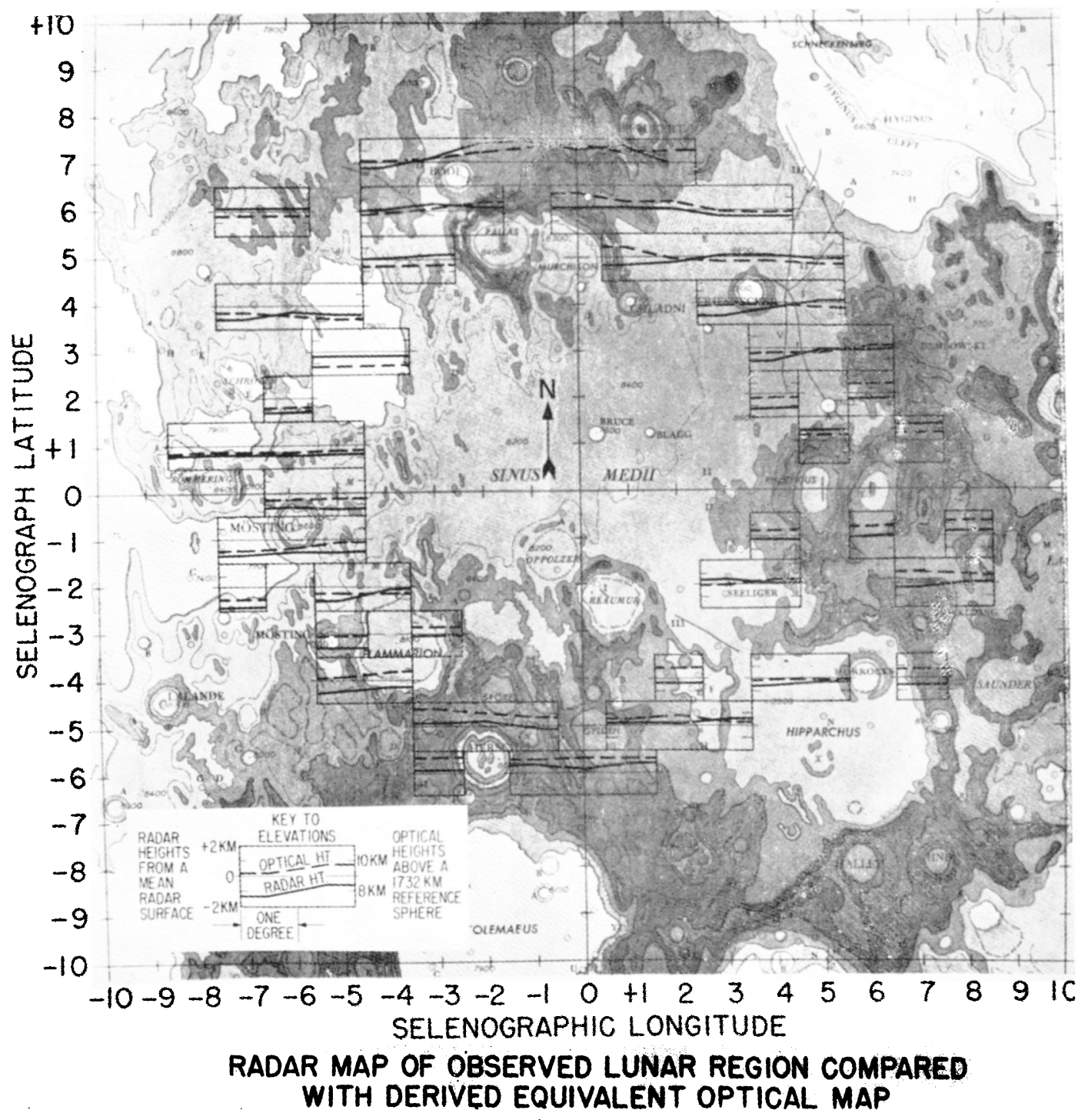

Fig. 7. - Radar map of observed lunar

region compared with a derived equivalent optical map. 
areas with less than three observations was also tried. However no important changes of the results were seen. The radar heights, as given in figure 7, are useful as reference surfaces for possible future radar investigations of orbital motion.

The topographic variations of the computed radar map were used to correct the original residuals. A plot of the corrected residuals is shown in figure $6 c$. It is seen that most of the large variations have been removed leaving only a periodic scale correction and the scatter of individual radar measurements. Using the corrected residuals of figure $6 c$ in a least square solution, a correction to the mean distance is derived which is referred to a radar mean surface of the Moon and does not depend on the topography of any particular area. The final residuals shown in figure $6 d$ contain only the scatter of the radar measurements. The standard error of each measurement is $\pm 300 \mathrm{~m}$, but the standard error of the correction to the mean distance is reduced to $\pm 15 \mathrm{~m}$ by the least square solution. This is negligible compared to the error contributed by the velocity of propagation.

So far only the effect of the lunar topography on the measured distance has been considered. In order to obtain the distance from the center of the Earth to the center of the Moon, additional computation has to be performed which requires information about the size and shape of the Earth and the Moon. Equation (3) shows the effect of the uncertainties of the Earth's and Moon's radius on the center-to-center distance correction. The largest uncertainty is contributed by $\Delta b$, the error of the Moon's radius, which exceeds those of $\Delta \rho$ and $\Delta r$ significantly. For the assumed value of $b=\mathrm{I} 738 \pm \mathrm{I} \mathrm{km}$ and $r=6369.936 \pm 0 . \mathrm{rm}$ the best estimate of the mean radar distance is

$$
\bar{s}=384 \text { 400.3 km }+0.712 \Delta r+\Delta b+\mathrm{I} .3 \Delta c .
$$

Recent geodetic determination of the Earth's equatorial radius (Kaula [4], Fischer [5]) indicate that a correction of about - roo m to the value of a given in table $\mathrm{I}$ is required. Hence, with $\Delta r=-0 . \mathrm{rkm}$, and allowing for an error of $\Delta b= \pm \mathrm{rkm}$, and $\Delta c= \pm 300 \mathrm{~m}$, the final result becomes

$$
\bar{s}=384400.2 \mathrm{~km} \pm 1.1 \mathrm{~km} .
$$

The accuracy of the value of $\bar{s}$ in the radar method is limited primarily by the uncertainties of the lunar radius and the velocity of radio wave propagation.

Conclusions. - The direct determination of the mean distance of the Moon by radar echoes may be compared with the optical determination ( $\left.{ }^{2}\right)$ (O'Keefe and Anderson [6]) where the occultation of a star by

() $s=384400.9 \pm 4.7 \mathrm{~km}$. 
the Moon was observed at selected stations when the star disappeared at the same point on the Moon's limb, thus eliminating the effect of the irregularities of the Moon's limb. O'Keefe and Anderson derived a value for the Earth's equatorial radius from their observations but it was remarked by Fischer [5] that the significant result of the contribution by $O$ 'Keefe and Anderson is the determination of the mean distance of the Moon; not that of the Earth's equatorial radius.

The radar method has the advantage of greater accuracy; on the other hand the full uncertainty of the Moon's radius enters into the radar determination which is not the case with the occultation determination.

The mean center-to-center distance of the Moon from the Earth may be related to the Earth's equatorial radius a by the formula

$$
a=2.6628776 \times 10^{-6} s^{\frac{3}{2}} g_{0}^{-\frac{1}{2}}(1+\mu)^{-\frac{1}{2}} \quad(:),
$$

in which $g_{0}$ is the acceleration of gravity at the equator, $\mu$. the mass ratio $\frac{\text { Moon }}{\text { Earth }}$.

With

$$
\begin{aligned}
\bar{s} & =3.844002 \times 10^{8} \mathrm{~m}, \\
g_{0} & =9.7803 \mathrm{~m} / \mathrm{s}^{2}, \\
\mu^{-1} & =8 \mathrm{I} .3 \mathrm{o}
\end{aligned}
$$

the result is

$$
a=6378167 \mathrm{~m} \text {. }
$$

It is evident that the value deduced for the Earth's equatorial radius will be modified if different values for $g_{0}$ and for $\mu$ are introduced.

Acknowledgments. - The authors are grateful to the following for their theoretical and technical assistances : R. H. Bruton, A. L. Branning, A. M. Wattenberg, and F. Wrigley.

\section{REFERENCES.}

[1] B. S. Yaplee, R. H. Bruton, K. J. Craig and N. G. Roman, Proc. I. R. E., vol. 46, I 958 , p. 293.

B. S. Yaplee, N. G. Roman, K. J. Craig and T. F. Scalan, Symposium on Radio Astronomy, Paris, (Stanford, Calif : Stanford University Press., r959, p. 19).

[2] D. Brouwer, R. H. Bruton, A. C. Miller and B. S. Yaplee Results of 1o-cm Lunar Radar Range Study presented to the XIIIth General Assembly of U. R. S. I., London, September 5-15, 1960 .

(3) This relation is discussed in more detail by D. BRouwer in Relation Among Some Important Astronomical Constants [7]. 
[3] F. Wrigley, K. J. Craig and B. S. Yaplee Parametric amplifiers in Radar Astronomy presented to the XIIIth General Assembly of U.R.S.I., London, September 5-15, 1960 .

[4] W. M. Kaula, Army Map Service Technical Report 24, r959, p. iо .

[5] I. Fischer, Astron. J., vol. 67, i 962, p. 373.

[6] J. A. O'Keepe and J. P. Axderson, Astron. J., vol. 57, r952, p. ro8; Errata, ibid, vol. 63, r958, p. 42 .

[7] D. BrouwÉR, Relation among some important astronomical constants to be presented at the I. A.U. Symposium No. 21 (The System of Astronomical Constants) Paris, I 963 . p. $24 \mathrm{I}$. 